\title{
IMPORTÂNCIA DA INTELIGÊNCIA EMOCIONAL PARA A EFETIVA [AÇÃO] DE UMA ASSISTÊNCIA DE ENFERMAGEM MAIS HUMANIZADA
}

\author{
Clecilene Gomes Carvalho ${ }^{1}$
}

\section{Recebido em: 28/05/2013 - Aprovado em: 15/07/2013 - Disponibilizado em: 15/08/2013}

\begin{abstract}
RESUMO
A equipe de enfermagem são os profissionais da saúde que mais tempo passam em contato com o paciente e com seus familiares dentro do ambiente de trabalho em situações de constantes mudanças emocionais. Visto que a Inteligência Emocional (IE) é o equilíbrio das emoções e atitudes de um indivíduo, por meio do qual ele desenvolve seu autocontrole e que a IE contribui com um numero muito maior das qualidades que nos tornam mais plenamente humanos e que a assistência humanizada é uma das prioridades da enfermagem foi que se realizou um estudo de revisão bibliográfica. O objetivo deste trabalho é compreender o qual a importância da IE para a efetivação de uma assistência mais humanizada que favoreça tanto o paciente, familiar quanto o profissional que executa o cuidado. Espera-se que este estudo seja positivo tanto para a manutenção da saúde mental do trabalhador como para o seu desenvolvimento profissional, bem como para possibilitar a continua busca pela excelência na assistência ao paciente.

Palavras chave: Inteligência emocional. Emoções Manifestadas. Esgotamento profissional. Humanização da assistência. Saúde do Trabalhador.

\section{IMPORTANCE OF EMOTIONAL INTELLIGENCE FOR A EFFECTIVE [ACTION] FOR A MORE HUMANIZED NURSING CARE}

\begin{abstract}
The nursing staffs are health professionals who spend more time in contact with the patient and their family members within the work environment of constant change in emotional situations. Since the Emotional Intelligence (EI) is the balance of emotions and attitudes of an individual, through which he develops his self-control and that the IE contributes a much greater number of qualities that make us more fully human and the humanized is one of the priorities of nursing was held a literature review. The objective of this study is to understand how important the IE for the realization of a more humanized care that favors both the patient and the family that runs the professional care. It is hoped that this study is positive both in maintaining mental health worker as to their professional development as well as to enable the continued pursuit of excellence in patient care.
\end{abstract}

Keywords: Emotional Intelligence. Expressed Emotion. Burnout, Professional. Humanization of Assistance. Occupational Health.

${ }^{1}$ Enfermeira pela Universidade Vale do Rio Verde (Unincor), campus Betim. Complementação pedagógica em Biologia. Especialização em Enfermagem do Trabalho. Membro da Associação Mineira de Hipertensão Pulmonar - AMIHAP. Pós graduanda em psicologia multifocal. Pós graduanda em saúde Publica com ênfase em ESF. E-mail: clecilene@globo.com 


\section{INTRODUÇÃO}

A incapacidade de lidar com as próprias emoções podem minar a experiência escolar, acabar com carreiras promissoras e destruir vidas. Para que um indivíduo tenha um bom desempenho ele necessita, alem da inteligência intelectual, de flexibilidade mental, equilíbrio emocional, dentre outros. É necessário, ainda, adquirir a capacidade de autoconhecimento/autopercepção, lidar com os sentimentos/autocontrole. É preciso controlar e administrar as emoções, levando-as a serem influenciadas pelos objetivos/automotivação, relacionando-se as pratica social e observando o emocional de outras pessoas/empatia. O conjunto destas competências é que podemos chamar de inteligência emocional. É a inteligência emocional que contribui com um número muito maior das qualidades que nos tornam mais plenamente humano (CURY, 2006; GOLEMAN, 2007).

Atualmente há um forte incentivo para a humanização do atendimento, na qual são valorizados o acolhimento, $\mathrm{o}$ respeito na relação profissional-paciente e a ampliação da qualidade técnica. Assim, a arte do cuidado em saúde não se reduz ao tratamento clínico do usuário (RICCI et $a l$, 2011). A humanização engloba uma série de diferentes aspectos referentes às ideias, aos valores e às práticas, envolvendo as relações entre os profissionais de saúde, os pacientes, os familiares e os acompanhantes, incluindo os procedimentos de rotina do serviço e a distribuição de responsabilidades dentro dessa equipe. No entanto, tais fatores tornam-se fragmentados se não for reconhecida a importância dos aspectos emocionais para o alcance da assistência mais humanizada (MACHADO; PRAÇA, 2006).

Sendo a equipe de enfermagem composta por profissionais da saúde que mais tempo passam em contato com o paciente e com seus familiares dentro do ambiente de trabalho em situações de constantes mudanças emocionais (CARVALHO; MAGALHÃES, 2011) e partindo da premissa da importância da assistência humanizada e que a inteligência emocional é aquela que mais contribui para as qualidades que nos tornam mais humanos (COSTA; FARIA, 2009) é que será realizado um estudo bibliográfico.

Visto que a IE é o equilíbrio das emoções e atitudes do individuo, por meio do qual ele desenvolve seu autocontrole, foi que se traçou o objetivo deste estudo de revisão que será buscar compreender qual a importância da inteligência emocional para o alcance de uma assistência mais humanizada que favoreça tanto o paciente, família quanto o profissional que executa o cuidado. Espera-se que este estudo seja positivo tanto para a manutenção da saúde mental do trabalhador como para o seu desenvolvimento profissional, bem como para possibilitar a continua busca pela excelência na assistência ao paciente.

\section{METODOLOGIA}

Trata-se de uma pesquisa de revisão bibliográfica do tipo qualitativo-dedutivo. Existem dois métodos básicos em pesquisas para descrever e estudar o comportamento humano: qualitativo e quantitativo. A abordagem qualitativa é aquela expressa em termos não numéricos, usando linguagem e imagens (GONZAGA; MONTEIRO, 2011 apud COZBY, 2006). Já o raciocínio dedutivo foi descrito pelos filósofos da Grécia Antiga, entre os quais se destaca Aristóteles. Cabe salientar que a palavra dedução deriva do verbo deduzir (do latim deducěre), que significa tirar conclusões de um princípio, de uma proposição ou suposição.

Este estudo de revisão bibliográfica abordou publicações em banco de dados eletrônicos do ano 2000 até 2011 por intermédio de buscas sistemáticas, porem para os livros utilizados não houve delimitação de data, visto que são poucos os relacionados diretamente com o tema. O levantamento em bancos de dados eletrônicos foi realizado nos indexadores MEDLINE (Literatura Internacional em Ciências da Saúde), PubMed, LILACS (Literatura Latino americana em Ciências da Saúde), SCIELO (Scientific Electronic Library Online).

Os objetivos serviram para classificar e estruturar a revisão bibliográfica. Uma vez classificada e estruturada, esta serviu de base para uma ampla análise do tema.

Foram utilizadas as seguintes palavras chaves: Relação enfermeiro-paciente, Enfermagem do Trabalho, Humanização da assistência, Inteligência emocional, estresse e emoção.

Para a definição dos descritores/palavras chave foi utilizado o DeCs - descritores em ciência da saúde. Uma linguagem única na indexação de artigos de revistas científicas, livros, anais de congressos, relatórios técnicos, e outros tipos de materiais. Sua finalidade é facilitar a pesquisa e recuperação de assuntos da literatura científica nas fontes de informação disponíveis na Biblioteca Virtual em Saúde (BVS) como LILACS, MEDLINE e outras. 
Foram encontrados artigos no LILACS que se adequavam aos objetivos propostos, porem somente o resumo estava disponível.

\section{RESULTADOS E DISCUSÃO}

A Inteligência Emocional envolve a capacidade de perceber acuradamente, de avaliar e de expressar emoções; a capacidade de perceber e/ou gerar sentimentos quando eles facilitam o pensamento; a capacidade de compreender a emoção e o conhecimento emocional; e a capacidade de controlar emoções para promover o crescimento emocional e intelectual (BUENO et al, 2003).

Portanto, a Inteligência Emocional é o equilíbrio das emoções e atitudes de um indivíduo, por meio do qual ele desenvolve seu autocontrole, sendo importante para o sucesso pessoal, social e profissional (HOFFMANN et al, 2010).

Mas para que possamos compreender a Inteligência Emocional - IE é necessário que se tenha claro a concepção de emoção (WOYCIEKOSKI; HUTZ, 2009).

A origem da palavra emoção é "movere", do latim mover. Foi acrescentado o prefixo "e" e ela passou a significar afastar-se. Portanto, emoção indica movimento e ação. São oito as nossas emoções primárias: ira, tristeza, medo, prazer, afeto, surpresa, nojo e vergonha. São os chamados núcleos emocionais básicos. Destas matrizes é possível existir uma infinidade de combinações. Emoção se refere ao sentimento que determina uma gama imensa de tendências para agir (GOLEMAN, 2007).

Em nosso repertório emocional, cada emoção desempenha uma função única, como revelam suas distintas assinaturas biológicas. Com novos métodos para investigar o corpo e o cérebro, os pesquisadores estão descobrindo mais detalhes fisiológicos de como cada emoção prepara o corpo para um tipo de resposta muito diferente. GOLEMAM, 2007, detalha em seu livro Inteligência emocional, mas precisamente nas páginas 32 a 33, quais são as alterações fisiológicas que cada tipo de emoção provoca, conforme a seguir:

- Com ira, o sangue flui para as mãos, tornando mais fácil pegar uma arma ou golpear um inimigo; os batimentos cardíacos aceleram-se, e uma onda de hormônios como a adrenalina gera uma pulsação, energia suficientemente forte para uma ação vigorosa.
- Com medo, o sangue vai para os músculos do esqueleto, como os das pernas, tornando-se mais fácil fugir - e faz o rosto ficar lívido, uma vez que o sangue é desviado dele (criando a sensação de que "gela"). Ao mesmo tempo, o corpo imobiliza-se, ainda que por um momento, talvez dando tempo para avaliar se esconder não seria uma melhor reação. Circuitos nos centros emocionais do cérebro disparam a torrente de hormônios que põe o corpo em alerta geral, tornandoo inquieto e pronto para agir, e a atenção se fixa na ameaça imediata, para melhor calcular a resposta a dar.

- Entre as principais mudanças biológicas na felicidade está uma maior atividade no centro cerebral que inibe os sentimentos negativos e favorece $o$ aumento da energia existente, e silencia aqueles que geram pensamentos de preocupação. Mas não ocorre nenhuma mudança particular na fisiologia, a não ser uma tranquilidade, que faz o corpo recuperar-se mais depressa do estímulo de emoções perturbadoras. Essa configuração oferece ao corpo um repouso geral assim como disposição e entusiasmo para qualquer tarefa imediata e para marchar rumo a uma grande variedade de metas.

- Amor, sentimentos afetuosos e satisfação sexual implicam estimulação parassimpática. O padrão parassimpático, chamado de "resposta de relaxamento", é um conjunto de reações em todo o corpo que gera um estado geral de calma e satisfação, facilitando a cooperação.

- O erguer das sobrancelhas na surpresa permite a adoção de uma varredura visual mais ampla, e também maior quantidade de luz a atingir a retina. Isso oferece mais informação sobre o fato inesperado, tornando mais fácil perceber exatamente o que está acontecendo e conceber o melhor plano de ação.

- Em todo o mundo, a expressão de repugnância parece à mesma e envia idêntica mensagem: alguma coisa desagrada ao gosto ou ao olfato, real ou metaforicamente. A expressão facial de nojo - o lábio superior se retorce para o lado, e o nariz se enruga ligeiramente - 
sugere uma tentativa primordial, como observou Darwin, de tapar as narinas contra um odor nocivo ou cuspir fora uma comida estragada.

- Uma das principais funções da tristeza é ajudar a ajustar-se a uma perda significativa, como a morte de alguém, ou uma decepção importante. A tristeza traz uma queda de energia e entusiasmo pelas atividades da vida, em particular diversões e prazeres e, quando se aprofunda e se aproxima da depressão, reduz a velocidade metabólica do corpo. Esse retraimento introspectivo cria a oportunidade para lamentar uma perda ou uma esperança frustrada, captar suas consequências para a vida e, quando a energia retoma, planejar novos começos.

Portanto as competências emocionais são essenciais nas interações sociais porque emoções alimentam funções comunicativas e sociais, além de conterem informações sobre os pensamentos e intenções das pessoas. A ocorrência de uma interação social positiva e satisfatória demandaria que os indivíduos percebessem, processassem e manejassem a informação emocional de forma inteligente (WOYCIEKOSKI; HUTZ, 2009 apud Lopes, Brackett, Nezlek, Schütz e Salovey 2004).

Desta forma, a emoção corresponderia a uma reação psicobiológica complexa, que envolveria inteligência e motivação, impulso para ação, além de aspectos sociais e da personalidade, que acompanhados de mudanças fisiológicas, expressariam um acontecimento significante para o bem-estar subjetivo do sujeito no seu encontro com o ambiente. Sob este prisma, a emoção seria parte determinada biologicamente e parte determinada pelo produto da experiência e do desenvolvimento humano no contexto sociocultural (WOYCIEKOSKI; HUTZ, 2009).

A emoção é o colorido necessário para a vida do indivíduo, é a visita inconveniente, a surpresa agradável ou desagradável, e a expressão mais pura e desenfreada das preferências e dos desgostos do indivíduo que rebeldemente cede espaço para a realização do pensamento (ALMEIDA, 2007).

3.1 O papel da inteligência emocional na assistência de enfermagem

Em enfermagem, as emoções assumem particular importância, pois sendo considerada uma profissão de relação, humanista, o desempenho profissional está diretamente relacionado com a capacidade das pessoas reconhecerem e controlarem as suas emoções (COSTA; FARIA, 2009).

Cada vez mais psicólogos têm apontado que a capacidade de compreensão das emoções em si e nos outros, constitui um aspecto crucial para uma vida satisfatória. Pessoas autoconscientes e sensíveis aos demais teriam maiores habilidades para administrar suas questões de forma mais sábia e adequada ao contexto, mesmo quando em situações adversas. Por outro lado, pessoas incapazes de reconhecer as próprias emoções e as alheias tenderiam a vivenciar problemas como desentendimentos constantes, frustrações e fracassos relacionais (WOYCIEKOSKI; HUTZ, 2009 apud Matthews et al, 2002).

A capacidade de compreender e analisar as emoções próprias e alheias culminaria numa melhor compreensão da relação da pessoa com os outros e com o ambiente que lhe cerca o que por sua vez, poderia promover regulação emocional mais adaptada, além de maior bem-estar (WOYCIEKOSKI; HUTZ, 2009 apud Salovey, Bedell, Detweiler, \& Mayer, 2000).

As emoções refletem-se quer no doente, quer nos cuidados prestados ao mesmo, e, por sua vez também as emoções do doente podem repercutir-se no profissional de saúde (DOMINGUES, 2009).

A IE é fundamental na relação terapêutica com o doente, verificando-se que os doentes se sentem melhor e aderem mais aos tratamentos quando percebem que o profissional de saúde consegue compreender o seu ponto de vista e colocar-se na sua perspectiva (DOMINGUES, 2009). O enfermeiro que consiga estabelecer com o seu cliente, um relacionamento empático, terá mais chances de mobilizar o potencial curativo interior da pessoa que este assiste, aumentando a eficácia da terapêutica prescrita.

É sabido que no contexto atual o enfermeiro tem que corresponder às exigências das instituições e dos clientes, requerendo habilidades, conhecimentos gerenciais, dinamismo, poder decisório, criatividade, liderança, cooperativismo, inteligência emocional, capacidade de barganha, plano de carreira, compromisso, dentre outros, para que se possa administrar a sua equipe com eficiência e , ainda, prestar uma assistência de qualidade e mais humanizada (WOYCIEKOSKI; HUTZ, 2009). 
O cuidado humanizado implica, por parte do cuidador, a compreensão do significado da vida, a capacidade de perceber e compreender a si mesmo e ao outro, situado no mundo e sujeito de sua própria história. Os profissionais de saúde devem compartilhar com seus pacientes experiências e vivências relacionadas ao cuidar (WALDOW; BORGES, 2011).

A humanização e o impacto das emoções assumem então um papel preponderante no contexto do cuidar, não podendo ser minorados ou ignorados, pois as consequências serão sentidas nos pacientes e nos profissionais (DOMINGUES, 2009).

Entende-se por humano a natureza humana, bondosa, humanitária, que tem o mesmo sentido de humanidade, no qual se incluiu benevolência, clemência, compaixão. Humanizar é a prática do humano. Logo, como humanos o que realizamos é humano, sendo, portanto, próprio ao ser humano visar o bem-estar da humanidade, tanto individual como coletivamente, isso é o verdadeiro sentido de humanizar (CORBANI; BRÊTAS; MATHEUS. 2009).

Humanização deve fazer parte da filosofia de enfermagem. $\mathrm{O}$ ambiente físico, os recursos materiais e tecnológicos não são mais significativos do que a essência humana. Esta sim irá conduzir o pensamento e as ações da equipe de enfermagem, principalmente do enfermeiro, tornando-o capaz de criticar e construir uma realidade mais humana. O cuidado humanístico não é rejeição aos aspectos técnicos, tão pouco aos aspectos científicos, o que se pretende ao revelar o cuidado é enfatizar a característica do processo interativo e de fruição de energia criativa, emocional e intuitiva, que compõe o lado artístico além do aspecto moral (BEDIN et al, 2004).

A IE constitui um campo de investigação relativamente novo, que traz consigo a proposta de ampliar o conceito do que é aceito como tradicionalmente inteligentes, incluindo nos domínios da inteligência aspectos relacionados ao mundo das emoções e sentimentos (WOYCIEKOSKI; HUTZ, 2009).

Deste modo, o significado das emoções no trabalho de enfermagem começa a ser progressivamente valorizado, pois embora a enfermagem envolva competências técnicas e cognitivas, aumenta o reconhecimento de que são as competências intra e interpessoais que melhor respondem às complexas exigências dos modernos sistemas de saúde. Os profissionais dos cuidados de saúde estão envolvidos em relações de ajuda e devem responder às emoções dos doentes e dos familiares, sendo difícil compreendê-las, a não ser que sejam empáticos. Deste modo, espera-se que os enfermeiros manifestem sensibilidade profissional para reconhecer a vulnerabilidade do doente e, simultaneamente, distingam, de forma responsável, entre os seus próprios sentimentos e os do paciente (COSTA; FARIA, 2009).

Aprender a ouvir e se fazer ouvir são tão importantes quanto passar informações técnicas. Tanto paciente quanto familiares sentem-se mais amparados e confiantes no tratamento quando percebem um real interesse por parte da equipe que os assistem. Esta sintonia por parte de paciente, família e equipe de saúde é possível graças a uma ferramenta básica da inteligência emocional, a empatia (GOLEMAN, 2007).

Ainda segundo o autor acima, a IE não é benéfica apenas para os que recebem o cuidado, mas como também para o cuidador, visto que os riscos para a saúde são maiores para aqueles que trabalham sob intensa pressão, alta exigência de desempenho e pouco ou nenhuma possibilidade de ter sob o próprio controle as tarefas que lhes são exigidas.

Umas das implicações para o trabalhador de enfermagem relacionada ao estado emocional é a Síndrome de Burnout, caracterizada por três componentes: exaustão emocional, diminuição da realização pessoal e despersonalização (BORGES; ARGOLO; BAKER, 2006; CARVALHO; MAGALHAES, 2011).

Dentre os vários aspectos comprometidos está a empatia, pois o individuo exausto emocionalmente não se percebe e desta forma não enxerga nem entende $\mathrm{o}$ sentimento alheio (GOLEMAN, 2007). Não se deixa envolver com os problemas e as dificuldades dos outros e as relações interpessoais são cortadas, como se ele estivesse em contato apenas com objetos, ou seja, a relação torna-se desprovida de calor humano, não tem empatia e assim o cuidado humanizado fica comprometido.

\subsection{Como treinar a inteligência emocional}

A proposta de que o ser humano é capaz de crescer com o aprendizado e com a análise de seus conteúdos emocionais (e subjetivos) foi apresentado à comunidade cientifica pelo modelo de Mayer e Salovey, onde os autores definiram a IE como a capacidade do indivíduo monitorar os sentimentos e as emoções dos outros e os seus, de discriminá-los e de utilizar essa informação para 
guiar o próprio pensamento $\mathrm{e}$ as ações (GONZAGA, MONTEIRO, 2011), mas só ficou, realmente, conhecido após a publicação de Goleman em 1995 do livro Inteligência Emocional (COBERO; MUNIZ, 2006; MUNIZ; MIGUEL, 2007). Depois vieram outras definições como a proposta por Cury em 1998 no seu livro Psicologia Multifocal.

De acordo com CURY, 2006:

- A Psicologia Multifocal apresenta a emoção como premissa da humanidade do individuo. Sociologicamente falando, tornar-se homem é um processo e, como tal, se dá gradativamente e durante uma trajetória, ou seja, sua história. Logo, o homem pode humanizar-se ou até mesmo ser desumanizado.

- Nos encontros e desencontros que constituem a dinâmica da vida em sociedade, há também encontros e desencontros psíquicos. Uma vez que o indivíduo possui a capacidade de pensar suas emoções, estas serão fundamentais na qualificação do tipo de pensamentos que este sujeito produz. Sua inteligência, sua capacidade intelectual, estará de fato vinculada à qualidade de suas emoções.

- A construção dos pensamentos e da personalidade humana está condicionada aos estímulos externos. Todavia a Teoria de Inteligência Multifocal apresenta um novo olhar no que tange à posição do indivíduo sobre sua postura diante dos cenários. $\mathrm{Na}$ perspectiva multifocal é possível que o indivíduo assuma a postura de autor. Quando o indivíduo age como ator, o que há é a representação de papéis em um contexto onde a autonomia e a essência do mesmo é abafada em prol de um bem estar coletivo. Ser autor significa que o indivíduo pode e deve (re) escrever sua história. Se há o livre arbítrio, necessário se faz fazer escolhas. A dor nesta perspectiva não é necessariamente o fim, mas essencialmente o início de uma nova etapa.

Não é possível para a natureza humana ter uma emoção continuamente prazerosa. Não existe como muitos psicólogos pensam equilíbrio emocional. A emoção passa por inevitáveis conflitos diários. Entretanto, a emoção é mais saudável quanto mais estável ela for e quanto mais perdurarem os sentimentos que alimentam o prazer e a serenidade (CURY, 2007).

É mais fácil e confortável explorar os estímulos extrapsíquicos, que sensibilizam nosso sistema sensorial, do que explorar os sofisticados processos de construção dos pensamentos, o nascedouro e canal de desenvolvimento das ideias, da organização da consciência existencial e das causas psicodinâmicas de nossas misérias, fragilidades, contradições emocionais (CURY, 2006).

Ainda segundo o autor acima, o ser humano é líder do mundo, mas não é líder de si mesmo. Sua construção de pensamentos não transforma facilmente suas emoções. $\mathrm{Se}$ os pensamentos tivessem plena liberdade de transformar o mundo psíquico, seria fácil tratar das depressões, superar o stress, transformar os psicopatas em pessoas humanistas e nos fazer viver num oásis de prazer, mesmo diante das nossas misérias sociais.

Felizmente a inteligência emocional dos indivíduos pode ser aumentada através do treino, alargando a amplitude de competências pessoais e sociais já manifestadas (COSTA; FARIA, 2009). Aprender a administrar as ideias negativas e gerenciar as emoções tensas é outro item da terapia multifocal (CURY, 2000). As capacidades essenciais da IE são desenvolvidas na infância, sendo, contudo, maleáveis e capazes de serem desenvolvidas e alteradas ao longo da vida (COSTA; FARIA, 2009). Neste aspecto a terapia multifocal, frequentemente, vai além das psicoterapias convencionais. Ela não trata apenas a doença psíquica, mas expande as funções mais importantes da inteligência do doente, até levá-lo a ser um pensador, um agente modificador da sua história, um administrador das suas emoções. Ela atua nos papéis da memória e nos fenômenos que constroem a inteligência e formam a personalidade (CURY, 2006).

Ainda segundo CURY, 2006, é possível treinar as emoções e rejuvenescê-las, conforme descrito a seguir:

Primeiro: Contemple o belo nos pequenos eventos da vida. Tenha sempre atividades fora da sua agenda pelo menos uma vez por semana. Valorize aquilo que o dinheiro não compra e que não dá ibope. Treine dez minutos por dia contemplar a anatomia das flores, gastar tempo vendo o brilho das estrelas, experimentar o prazer de penetrar no mundo das pessoas. Não viva em função de 
grandes eventos, aprenda a extrair o prazer dos pequenos estímulos da rotina diária.

Segundo: Irrigue o palco da mente com pensamentos agradáveis. Treine trazer diariamente à sua memória aquilo que lhe traz esperança, serenidade e encanto pela vida. Pense em conquistar pessoas e em superar seus obstáculos. Pense em ser íntimo do Autor da vida e conhecer os mistérios da existência. Seus maiores inimigos estão dentro de você. Não se deixe derrotar ou se perturbar por pensamentos que lhe roubam a tranquilidade e o prazer de viver. Treine ver o lado positivo de todas as coisas negativas. Os negativistas veem os raios, os que renovam a emoção veem a chuva; os negativistas veem o caos e os que renovam a emoção veem uma oportunidade de começar tudo de novo.

Terceiro: Pense como um adulto e sinta como uma criança. Treine pensar com lucidez, serenidade e consciência, mas tenha a simplicidade e a espontaneidade de uma criança. Treine ser uma pessoa agradável em sua empresa ou família. Cumprimente todas as pessoas do ambiente, aperte suas mãos e sorria. Uma pessoa é mais jovem emocionalmente quanto mais agradável ela for.

Quarto: Não faça o velório antes do tempo, não sofra por antecipação. Pense nos problemas e nas situações que ainda não aconteceram o suficiente para planejar determinadas atitudes, mas jamais gravite em torno deles. Os que sofrem por antecipação treinam ser infelizes, gastam uma energia vital, fazem de suas vidas um canteiro de preocupações e stress.

Quinto: Proteja sua emoção nos focos de tensão. Não faça de sua emoção uma lata de lixo social. Treine protegê-la nos focos de tensão, não permita que as ofensas, as perdas e as frustrações invadam sua emoção. Você deve ser um pequeno peixe num mar de tensão. Você está no mar, mas o mar não está em você. Não se esqueça de que pensar muito aumenta a ansiedade e a ansiedade crônica envelhece a emoção.

Sexto: Não seja carrasco de si mesmo. Não coloque metas inatingíveis para si. Reconheça a sua falibilidade. Mesmo não querendo errar, você falhará muitas vezes. Falhará, talvez, até em lições que já aprendeu. Não se destrua por sentimento de culpa nem cobre dos outros, o que eles não podem dar. Comece tudo de novo quantas vezes for necessário. Aprenda a ser compreensivo e paciente consigo mesmo. Os que são carrascos de si mesmos encurtam a primavera da emoção.
Cada emoção oferece uma disposição distinta para agir; cada uma nos põe numa direção que deu certo no lidar com os recorrentes desafios da vida humana (GOLEMAN, 2007).

$\mathrm{O}$ quadro 1 a seguir demonstra as 05 capacidades de Inteligência Emocional segundo Goleman. Segundo este autor estas habilidades são essenciais para pessoas que trabalham em equipe como é o caso da enfermagem.

QUADRO 1 - As cinco capacidades de Inteligência Emocional de Goleman

\begin{tabular}{|c|c|}
\hline \multicolumn{2}{|c|}{$\begin{array}{l}\text { As cinco capacidades de Inteligência Emocional de } \\
\text { Goleman }\end{array}$} \\
\hline $\begin{array}{l}\text { Conhecer as } \\
\text { próprias } \\
\text { emoções/Autop } \\
\text { ercepção }\end{array}$ & $\begin{array}{l}\text { Reconhecer as emoções } \\
\text { no momento em que elas } \\
\text { ocorrem } \\
\text { Monitorar as emoções a } \\
\text { cada momento }\end{array}$ \\
\hline $\begin{array}{ll}\text { Gerir } & \text { as } \\
\text { emoções/ } & \\
\text { autocontrole } & \end{array}$ & $\begin{array}{l}\text { Gerir as emoções a fim } \\
\text { de serem apropriadas } \\
\quad \text { Capacidade de } \\
\text { Cacalmar se } \\
\text { Capacidade } \\
\text { ultrapassar situações } \\
\text { ansiedade ou irritabilidade }\end{array}$ \\
\hline Automot & $\begin{array}{l}\text { Direcionar as emoções } \\
\text { ao serviço de um objetivo } \\
\text { Adiar as recompensas e } \\
\text { controlar a impulsividade }\end{array}$ \\
\hline Empatia & $\begin{array}{l}\text { Compreensão do que os } \\
\text { outros querem ou precisam; } \\
\text { Habilidade } \\
\text { comunicação interpessoal de } \\
\text { forma espontânea e não verbal, e } \\
\text { de harmonizar-se com as } \\
\text { pessoas. }\end{array}$ \\
\hline $\begin{array}{l}\text { Gerir } \\
\text { relacionamentos } \\
\text { /praticas sociais }\end{array}$ & $\begin{array}{l}\text { Capacidade } \\
\text { relacionamento interpessoal e de } \\
\text { trabalho em equipe; } \\
\text { Capacidade de gerir as } \\
\text { emoções dos outros e interagir de } \\
\text { forma construtiva. }\end{array}$ \\
\hline
\end{tabular}

Fonte: COSTA, 2009, pag. 33.

Segundo GOLEMAM, 2007, a recomendação de Sócrates, conhecer a ti mesmo, é a pedra de toque da inteligência emocional: a consciência de nossos sentimentos no momento exato em que ocorrem. E desta forma a Teoria da Inteligência Multifocal de CURY, 2006, a partir deste reconhecimento propõe técnicas psicológicas para sermos líderes de nós mesmos, 
objetivando reeditar as memórias negativas e produzir janelas paralelas da memória. Estas técnicas são principalmente duas:

1. DCD (duvidar, criticar, determinar) que deve ser utilizada durante e após os focos de tensão.

2. Mesa redonda do eu, utilizada após os focos de tensão de forma constante.

DCD - duvidar, criticar e determinar. Devemos duvidar das ideias dramáticas que muitas vezes alimentamos; duvidar das circunstâncias, pensamentos e fatos que nos deixem deprimidos, tristes, magoados, ansiosos; duvidar de sentimentos de inferioridade. Duvidar da incapacidade de ser feliz.

A partir daí, Criticar diariamente tais pensamentos, posturas e comportamentos. Com um detalhe: em nós mesmos, não nos outros; Criticar pensamentos negativos, ideias perturbadora, angústias, medos e inseguranças que surjam interiormente.

E, por fim, determinar ser feliz, equilibrado, sereno, harmonioso consigo mesmo, tranquilo; conquistar o que mais ama e ser líder de si mesmo, ao invés de deixar-se conduzir. Determinar reações e comportamentos altruístas, ideias e posturas positivas que lhe tragam alegria, bem estar e equilíbrio emocional. A emoção aprecia uma ordem, mas domina pessoas passivas.

A Mesa-redonda do eu é uma prática de autoquestionamento e reflexão, para isso: reserve 15 minutos por dia para reflexão e faça críticas, debates e questionamentos sobre o que lhe parecer negativo e doentio. Lembre-se: a renovação, a determinação e a persistência nos oferecem a força necessária para transformarmos nossa vida e a maneira como nos colocamos nela, em um espiral ascendente de melhoria contínua e crescimento baseado em nossos princípios e valores.

\section{CONCLUSÃO}

A própria natureza da enfermagem exige que os profissionais enfermeiros sejam emocionalmente inteligentes. Isto decorre porque os enfermeiros fornecem cuidados através de relações humanas, sendo responsáveis em contribuir para com estas relações e as emoções que as envolvem. Logo, entender e lidar com a emoção é habilidade nuclear na enfermagem, sendo requisito profissional da prática de enfermagem humanizada. Desta forma o profissional que tem inteligência emocional exerce melhor suas atividades, pois é capaz de lidar com as emoções e principalmente com os sentimentos despertados por elas.

\section{REFERENCIAS}

ALMEIDA, Ana Rita S. A emoção na sala de aula. 6 ed. Pag. 83. SP: Papirus, 2007.

BEDIN, Eliana et al.. Humanização da assistência de enfermagem em centro cirúrgico. Revista Eletrônica de Enfermagem, v. 06, n. 03, $2004 . \quad$ Disponível em: http://www.fen.ufg.br/revista/revista6_3/13_Revis ao3.html. Acesso em 30 de março de 2012.

BUENO, José M.H. et al. Inteligência emocional: Um estudo de validade sobre a capacidade de perceber emoções. Psicologia: Reflexão e Crítica, 2003, 16(2), pp. 279-291 Disponível em: http://www.scielo.br/pdf/prc/v16n2/a08v16n2.pdf. Acesso em 22 de fevereiro de 2012.

CARVALHO, Clecilene G.; MAGALHÃES, Sergio R.. Sindrome de burnout e suas consequencias nos Profissionais de enfermagem. Revista da Universidade Vale do Rio Verde, vol. 9, n. 1, Betim, 2011. Disponivel em

http://revistas.unincor.br/index.php/revistaunincor

/issue/view/13 doi: http://dx.doi.org/10.5892/RUVRV.91.200210.

Acesso em: 22 de março de 2012.

COBERO, Cláudia; Primi, Ricardo; MUNIZ, Monalisa. Inteligência emocional e desempenho no Trabalho:. Hum Estudo com MSCEIT, BPR-5 e 16PF Paidéia (Ribeirão Preto), Ribeirão Preto, v 16, n. 35, dezembro 2006. Disponível a partir do $<$ http://www.scielo.br/scielo.php?script=sci_arttex t\&pid=S0103-

$863 X 2006000300005 \& \operatorname{lng}=e n \& n r m=i s o>$. acesso em 20 de março de 2012. http://dx.doi.org/10.1590/S0103-

863X2006000300005.

BORGES, Livia de Oliveira; ARGOLO, João Carlos Tenório; BAKER, Maria Christina Santos. Os valores organizacionais e a Síndrome de Burnout: dois momentos em uma maternidade pública. Psicol. Reflex. Crit. , Porto Alegre, v. 19, n. 1, 2006. Disponível em: http://www.scielo.br/scielo.php?script=sci_arttext \&pid=S0102$79722006000100006 \& \operatorname{lng}=$ pt\&nrm=iso. Acesso em 20 de fevereiro de 2012. 
COBERO, Cláudia; Primi, Ricardo; MUNIZ, Monalisa. Inteligência emocional e desempenho no Trabalho:. Hum Estudo com MSCEIT, BPR-5 e 16PF Paidéia (Ribeirão Preto), Ribeirão Preto, v 16, n. 35, dezembro 2006. Disponível a partir do $<$ http://www.scielo.br/scielo.php?script=sci_arttex t\&pid=S0103-

$863 X 2006000300005 \& \operatorname{lng}=e n \& n r m=i s o>$. Acesso em 26 de março de 2012. http://dx.doi.org/10.1590/S0103-

863X2006000300005.

CORBANI, Nilza Maria de Souza; BRETAS, Ana Cristina Passarela; MATHEUS, Maria Clara Cassuli. Humanização do Cuidado de Enfermagem:. Que o ISO e Rev. bras. enferm. , Brasília, v. 62, n. 3, junho de 2009. Disponível a partir de

$<$ http://www.scielo.br/scielo.php?script=sci_arttex t\&pid=S0034-

$71672009000300003 \& \operatorname{lng}=e n \& n r m=i s o>$. acesso em 17 de fevereiro de 2012. http://dx.doi.org/10.1590/S0034-

71672009000300003.

COSTA, Ana C.; FARIA, Luísa. A inteligência emocional no contexto de enfermagem: estudo exploratório com o questionário de competência emocional (QCE). Actas do $\mathrm{X}$ Congresso Internacional Galego-Português de Psicopedagogia. Braga: Universidade do Minho, $2009 . \quad$ Disponivel em: http://www.educacion.udc.es/grupos/gipdae/congr eso/Xcongreso/pdfs/t9/t9c295.pdf. Acesso em 17 de fevereiro de 2012.

COSTA, Alexandra M.G. Inteligência emocional e assertividade nos enfermeiros. INSTITUTO POLITÉCNICO DE BEJA ESCOLA SUPERIOR DE EDUCAÇÃO DE BEJA. Faro, 2009. Dissertação para a obtenção do grau de mestre em Psicologia - Psicologia da Saúde. Disponível em: http://sapientia.ualg.pt/bitstream/10400.1/240/1/Di sserta\%C3\%A7\%C3\%A3o\%20Intelig\%C3\%AAn cia\%20Emocional\%20e\%20Assertividade\%20nos \%20Enfer.pdf. Acesso em 20 de março de 2012.

CURY, Augusto, Treinando a emoção para ser feliz: nunca a auto estima foi tão cultivada no solo da vida. São Paulo: Editora Planeta do Brasil, 2007, p. 26-28, 31 - 40. Disponível em: http://www.docstoc.com/docs/1045752/AugustoCury---Treinando-a-Emo\%C3\%A7\%C3\%A3opara-Ser-Feliz. Acesso em: 23 de março de 2012.
CURY, Augusto, Inteligência Multifocal, Cultrix: São Paulo, 2006.

DOMINGUES, Ana R. T.. Inteligência Emocional, Empatia e Satisfação no Trabalho em Médicos. Dissertação de Mestrado. Universidade do Porto Faculdade de Psicologia e de Ciências da Educação. Portugal, 2009. Disponível em: http://repositorioaberto.up.pt/bitstream/10216/54995/2/72818.pdf. Acesso em: 23 de março de 2012.

GONZAGA, Alessandra Rodrigues; MONTEIRO, Janine Kieling. Inteligência Emocional no Brasil:. Hum panorama da Pesquisa Científica Psic:. Teor. e Pesq. , Brasília, v. 27, n. 2, junho de 2011. Disponível a partir de $<$ http://www.scielo.br/scielo.php?script=sci_arttex $\mathrm{t} \&$ pid=S0102-

$37722011000200013 \& \operatorname{lng}=\mathrm{en} \& \mathrm{nrm}=\mathrm{iso}>$. acesso em 17 de março de 2012. http://dx.doi.org/10.1590/S0102-

37722011000200013.

GOLEMAN, Daniel, ph.D. A inteligência emocional: a teoria revolucionaria que define o que é ser inteligente. Rio de Janeiro - Ed. Objetiva, $10^{\circ} \mathrm{ed}, 2007$.

HOFFMANN, Michael et al. The impact of stroke on emotional intelligence. BMC Neurol, Florida, 2010; n. 103, vol. 10. http://www.ncbi.nlm.nih.gov/pmc/articles/PMC29 87854/?tool=pubmed. doi: 10.1186/1471-237710-103. Acesso em 12 de fevereiro de 2012.

MACHADO, Nilce Xavier de Souza; Praça, Neide de Souza. Centro de parto normal, ea Assistência obstétrica centrada NAS Necessidades da Parturiente. Rev. esc. enferm. USP , São Paulo, v 40, n. 2, junho de 2006. Disponível a partir do $<$ http://www.scielo.br/scielo.php?script=sci_arttex t\&pid=S0080-

$62342006000200017 \& \operatorname{lng}=\mathrm{en} \& n \mathrm{~nm}=\mathrm{iso}>$. Acesso em $17 \quad$ março 2012. http://dx.doi.org/10.1590/S008062342006000200017.

NASCIMENTO, Slvana H.. As relações entre inteligência emocinal e bem estar no trabalho. Universidade Metodista de São Paulo. Dissertação de mestrado em psicologia da saúde. São Bernardo do Campo, 2006. Disponivel em: http://ibict.metodista.br/tedeSimplificado/tde_arq uivos/2/TDE-2007-01-03T135525Z- 
125/Publico/Silvana\%20Helal\%20Nascimento.pdf . Acesso em 18 de março de 2012.

RICCI, Natalia Aquaroni et al . O hospital-escola de São Carlos: análise do funcionamento por meio da satisfação dos usuários. Ciênc. saúde coletiva, Rio de Janeiro, 2012 . Available from $<$ http://www.scielosp.org/scielo.php?script=sci_art text\&pid=S1413-

$81232011000700044 \& \operatorname{lng}=$ en\&nrm=iso $>$. access on $17 \quad$ Março 2012. http://dx.doi.org/10.1590/S1413-

81232011000700044.

MUNIZ, Monalisa; PRIMI, Ricardo; MIGUEL, Fabiano Koich. Investigação da inteligência emocional como fator de controle do stress em guardas municipais. Psicol. teor. prat., São Paulo, v. 9, n. 1, jun. 2007 . Disponível em $<$ http://pepsic.bvsalud.org/scielo.php?script=sci_ar ttext\&pid=S1516

$36872007000100003 \& \operatorname{lng}=$ pt\&nrm=iso $>$. Acessos em 17 março 2012.

WALDOW, Vera Regina; BORGES, Rosália Figueiró. Cuidar e humanizar: Relações e significados Acta paul. enferm., São Paulo, v. 24, n. 3, de 2011. Disponível a partir de $<$ http://www.scielo.br/scielo.php?script=sci_arttex t\&pid=S0103-

$21002011000300017 \& \operatorname{lng}=e n \& n r m=i s o>$. Acesso em 15 de março de 2012. http://dx.doi.org/10.1590/S0103-

21002011000300017.

WOYCIEKOSKI, Carla; Hutz, Claudio Simon. Inteligência Emocional: Teoria, Pesquisa, Medida, Aplicações e controvérsias. Psicol. Reflexo. Crit. , Porto Alegre, v. 22, n. 1, 2009. Disponível a partir de $<$ http://www.scielo.br/scielo.php?script=sci_arttex t\&pid=S0102-

$79722009000100002 \& \operatorname{lng}=$ en\&nrm=iso $>$. acesso em 15 de março de 2012. http://dx.doi.org/10.1590/S0102-

79722009000100002. 